\title{
Plant disease diagnosis: technological advancements and challenges
}

\author{
REKHA BALODI* ${ }^{*}$, SUNAINA BISHT ${ }^{2}$, ABHIJEET GHATAK ${ }^{3}$ and K.H. RAO ${ }^{1}$ \\ ${ }^{1}$ National Academy of Agricultural Research and Management, Hyderabad 500 030, Telangana, India \\ ${ }^{2}$ ICAR-Indian Institute of Maize Research, New Delhi 110 012, India \\ ${ }^{3}$ Department of Plant Pathology, Bihar Agricultural University, Sabour 813210 , Bihar, India
}

Received: 24 April 2017/ Accepted: 6 June 2017/ Published online: 24 July 2017

(C) Indian Phytopathological Society 2017

\begin{abstract}
Plant diseases cause substantial losses in yield of plants, leading to huge economic losses. Accurate identification and diagnosis of plant diseases are very important in the era of climate change and globalization for food security as well as prevention of the spread of invasive pests/pathogens. In addition, for an efficient and economical management of plant diseases accurate, sensitive and specific diagnosis is necessary. The science of plant disease diagnosis has evolved from visual inspection and identification of plant diseases to detect with high-throughput serological techniques like enzyme-linked immunosorbent assay (ELISA) and molecular methods such as polymerase chain reaction (PCR). With the applications of bioinformatics in plant pathology, identification of specific motifs, DNA sequences has become possible, which ultimately increase the accuracy of modern techniques in plant disease diagnosis. Though advances have been made in every aspect of diagnosis of plant diseases; increasing sensitivity and specificity have remained the key area for development. This review briefly describes the various techniques used for plant disease diagnosis and their evolution to meet the contemporary challenges.
\end{abstract}

Keywords: Detection, diagnosis, ELISA, plant diseases, PCR

Plant diseases caused by emerging, re-emerging and chronic/endemic pathogens cause acute economic loss in plant systems; losses of around $10 \%$ are reported due to plant diseases (Strange and Scott, 2005). Plant diseases exploit plants resulting in low productivity which act as the threat for food security. Food security along with nutritional security is the area of concern globally. The increase in human population will require additional $70 \%$ of food by 2050 (Godfray et al., 2010), which requires an increase in agricultural productivity.

Agricultural productivity is limited by many factors, among which plant diseases are of major concerns. Plant diseases not only hamper the productivity of plants but also affect the human and livestock health, which contributes to environmental damage. In major cereals biotic stress cause loss of over $23 \%$ of estimated attainable yield (FAO, 2009), in addition, postharvest losses due to diseases and substandard of the quality of produce are reported to be $30-40 \%$ (Fang and Ramasamy, 2015). Further, approximately $\$ 40$ billion are lost annually due to plant diseases in the United States alone. Climate change and increased human mobility are also contributing to losses due to plant diseases (Miller et al., 2009). Considering the economic, social and environmental consequences of plant diseases, detection of phytopathogens is retaining the attention of concern

\footnotetext{
*Corresponding author: balodirekha30@ gmail.com
}

within and outside the plant pathology community (Brownlie et al., 2006).

Further, losses due to plant diseases not only hamper the crop productivity but also are threat to global food and nutritional security, which lead to change in demographic pattern and affect livestock health (Miller et al., 2009). Specific and sensitive detection of phytopathogens is required for efficient and effective plant disease management. Inaccurate plant disease diagnosis may lead to failure of management strategies; and hence, is responsible for crop losses and overall loss in trade. The loss in trade is further aggravated by inadequate sanitary and phytosanitory (SPS) measures (Miller et al., 2009). Though the government is responsible to protect agricultural and natural plant systems in their countries from invasive pathogens, at the same time it is required that measures should be adopted to prevent their own endemic pathogens to becoming invasive species in other countries.

Detection of phytopathogens in hosts as well as in the environment (Fig. 1) such as soil, water and air is required to quantify the pathogen inoculum, assess effectiveness of methods of managing pathogens, certification of seed and planting material, quantification of pathogen population and yield loss, estimation of pathogen variation, evolution of new races and selection of sources of resistance, resolve the components of 


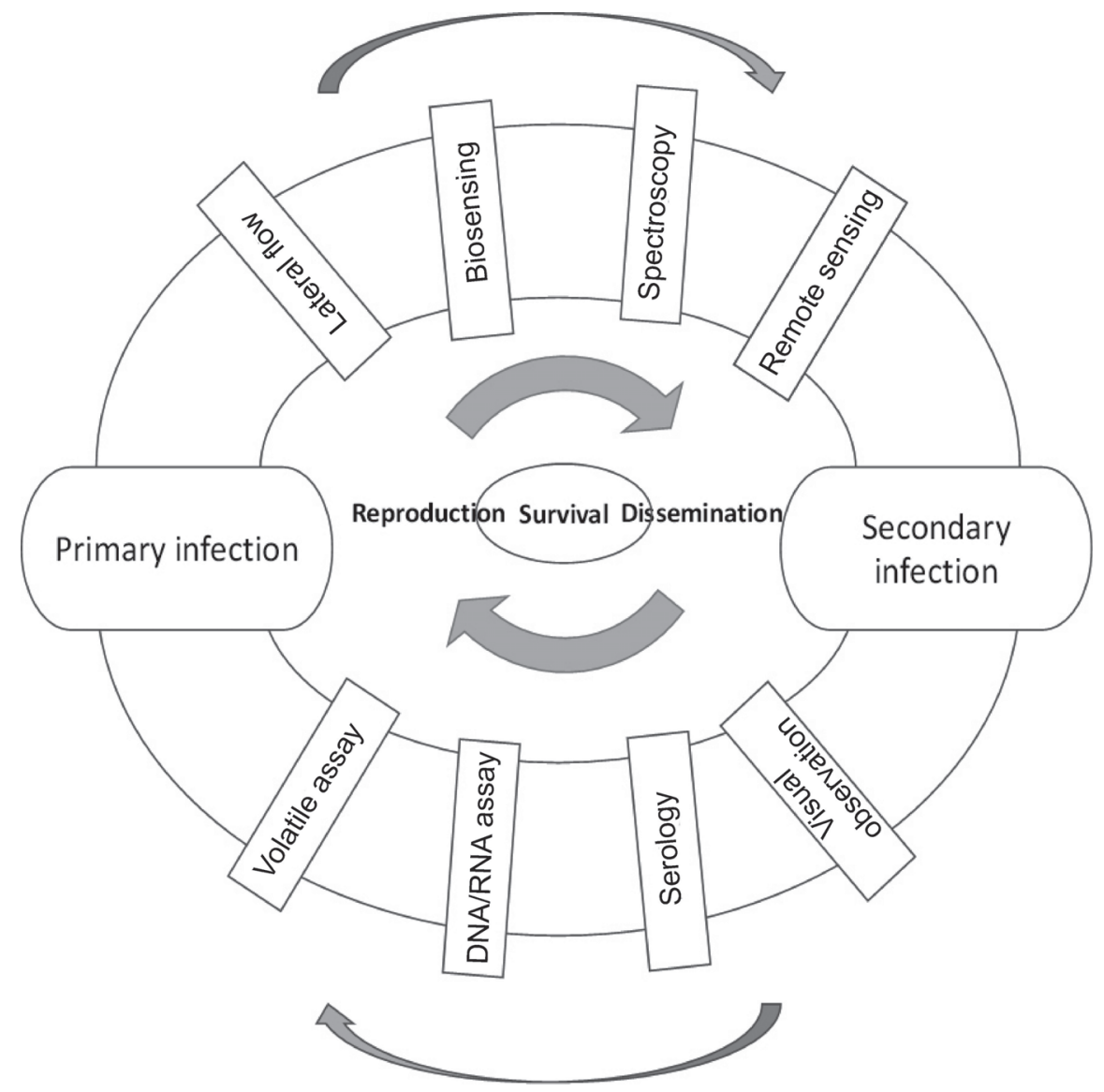

Fig. 1. Methods of detection of plant pathogens at various stages of disease cycle

complex diseases induced by two or more pathogens and study the interrelationships of interactions between plants and pathogens to have an insight into the phenomenon of pathogenesis and gene functions (Narayanasamy, 2011).

In order to adopt a seed health testing technique it should fulfil following requirements: (i) the time and labour required for testing should be reasonable, and (ii) the result should be fair in estimating the amount of seed borne inoculum and its impact on seed germination and development of disease in field. The results should be reproducible. With the advancement of technology; detection and diagnosis methodologies have become more sensitive and accurate, which is also need of current time because of higher importance of the quarantine measures for decreasing the spread of the invasive, destructive pathogens to previously uninvaded areas. Detection protocols used for the diagnosis or quarantine measures should be reproducible, repeatable and should have minimum false results. All detection methods should be sensitive to pathogen concentration, genetic variability within a target pathogen population, and similarities between the target and other organisms (Candresse et al., 2014; Martin et al., 2016).

\section{Methods of plant pathogen detection}

For many years knowledge of the physiological method of host-pathogen interaction for many plant-pathogen systems has been lacking. Recently, there is development of quantitative high-throughput image-based methods for phenotyping plant growth and development. These methods help in study the change in plant physiology due to pathogen infection, which further helps in the study the mechanisms of disease symptom development. Some of the methods for the detection of plant pathogen are shown in Fig. 1.

\section{Visual inspection}

Visual inspection of plant germplasm and subsequent selection of healthy material is one of the simplest methods of plant pathogen detection. The visual inspection can be done by different methods i.e. visible light imaging, chlorophyll florescence imaging, hyper spectral imaging and thermal imaging (Mutka and Bart, 2015). These methods are highly influenced by the environmental and biological factors. Further, traditional methods of scoring disease severity are not reliable for estimating disease in the population due to lack of uniformity and requirement of expertise in the procedure (Mutka and Bart, 2015). Visual inspection may not be helpful in asymptomatic plants or less virulent pathogens e.g. in case of Xylella fastidiosa many host plants remain symptomless. Further differentiating closely related strains may be difficult with visual inspection. This method of diagnosis is highly influenced by the expertise of identifying symptoms and differentiating them from 


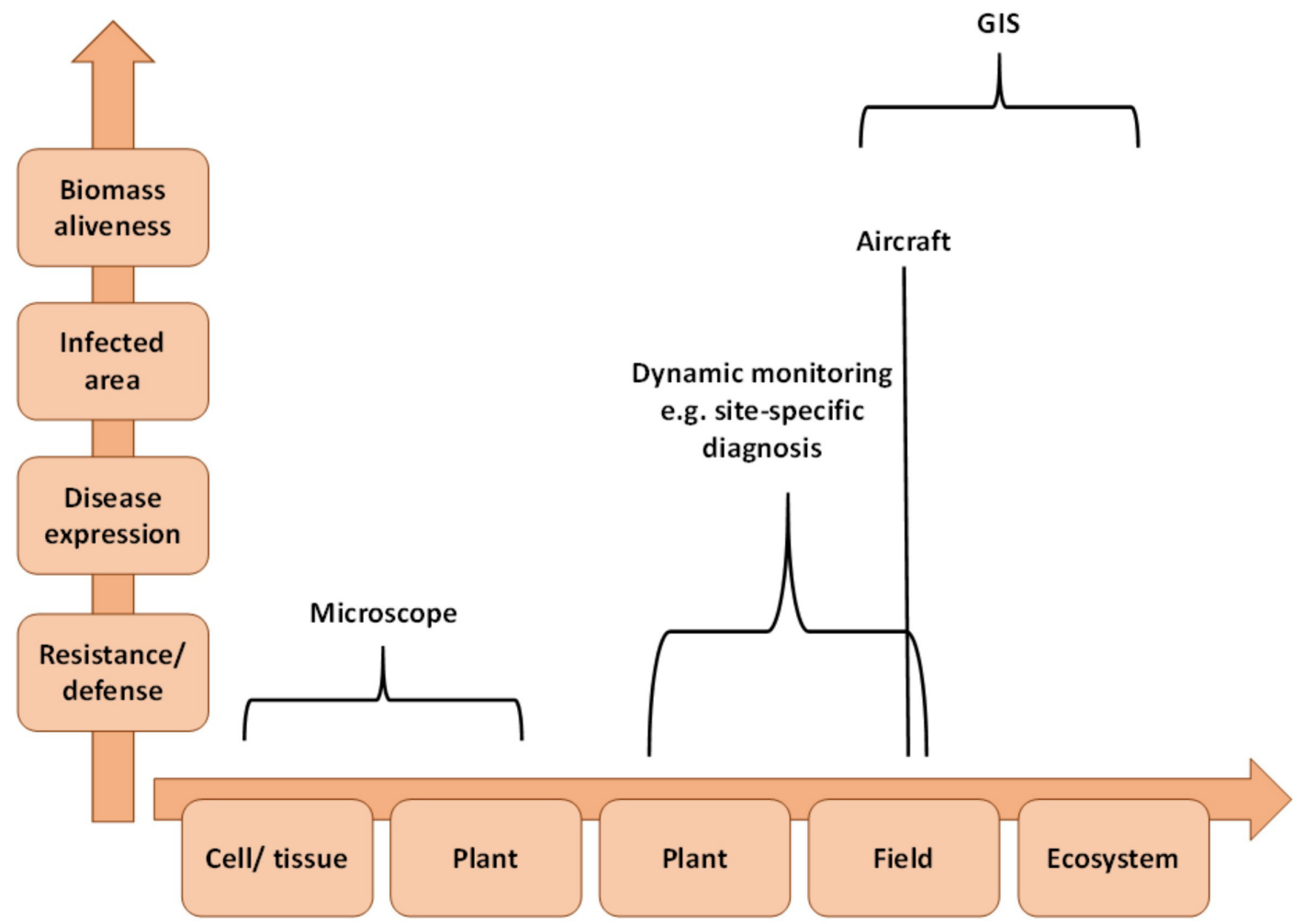

Fig. 2. Problem-wise detection strategies using different tools at different scales (modified from Mahlein, 2016)

closely related symptoms caused by other factors (Riley et al., 2002).

Plant phenomics has arisen as an emerging area in plant sciences (Mutka and Bart, 2015) to study the interaction between genotype and phenotype. These methods are non-destructive i.e. data can be collected from the same organism for a long time, amenable to automation for studying large sample size. This technique is suitable for plant pathogen interactions as the technique detect spatial patterns of heterogenity and localized responses can be visualized. There are various methods of phenotyping plant samples like chlorophyll fluorescence imaging, hyperspectral imaging, thermal imaging (Mutka and Bart, 2015). Though the plant phenomics appears very promising for plant disease diagnosis but differentiation of the diseases at later stages will be difficult using only this technique. Plant diseases which develop asymptomatically or have internal symptoms are difficult to identify using image based systems. For example, the group of fungi known as Fusarium spp. cause maize ear rot disease, and certain environmental conditions promote asymptomatic Fusarium infections with accumulation of dangerous mycotoxins in the host tissue (Murillo-Williams and Munkvold, 2008; Mesterházy et al., 2012). At the same time technologies which are specific for a particular disease are superior options for plant disease diagnosis compared to image-based phenotying because of specificity and sensitivity. Multidisciplinary approaches involving biologists, computer scientists, engineers etc. can be viable alternative for the development of image based methodologies and at the same time it is essential to improve existing methodologies for accurate plant disease diagnosis. Along with visual inspection, diagnosis using microscopy can be done for studying fungi and insects. Identification of virus and phytoplasma can be done using electron microscopy by particle morphology. But microscopy has low sensitivity and pathogen in low titre cannot be identified.

\section{Serodiagnostics}

Visual diagnosis of plant pathogens in plants expressing symptom would have prerequisite of extensive experience with plant disease diagnosis and then isolation of the pathogen. However, the accuracy of the same is not mandatorily identical for all the attempts. Moreover, the detection of the pathogen in asymptomatic samples (potato tuber, wood etc) or seed materials have very limited chances of success to get properly diagnosed. Even so the importance of accurate detection and then proper diagnosis procedure would contribute the plant health management more promisingly. Therefore, inventions of accurate detection methods are helping to develop better management strategies at first, and secondly, the rapid or quick detection tool, particularly a handy-one which could be used at the field, would definitely contribute in getting success for management. Recently, a handy-detection kit was developed for potato virus, which can be easily used at the field by the growers (Ansar and Singh, 2016).

Plant pathogens like viruses cannot be cultivated artificially; to address this issue serological assays were developed, which are used to detect other plant 
pathogens too (Caruso et al., 2002). Serological detection of plant pathogens involves identification of disease based on antibodies supported by colour change in the assay. Antibodies are composed of immunoglobulin (Ig) proteins produced in the body of an animal in response to the presence of antigens, which are usually foreign proteins, complex carbohydrates, polynucleotides or lipopolysaccharides. Each antibody is specific to a particular antigen and will bind to it. Most commonly used serological method is ELISA (Enzyme Linked Immunosorbent Assay) which was earlier developed for the detection of plant viruses (Clark, 1981). It was modified according to the specific needs of the detection assay viz., Direct ELISA (conjugated antibody-enzyme complex directly binds to antigen) and Indirect ELISA (antigen does not directly bind to antibody - enyme conjugate) (Paul Khurana, 2006). Presently ELISA is used extensively for detection of plant pathogenic fungi and bacteria using monoclonal and polyclonal antisera.

Various polyclonal and monoclonal antisera techniques like enzyme-linked immunosorbent assay (ELISA), dot-blot immune-binding assays for Southern rice black-streaked dwarf disease (Wang et al., 2012), immunostrip assays, western blots, and serologically specific electron microscopy (SSEM) in phytoplasma diseases (Musetti et al., 2002) are widely used to detect different groups of plant pathogens. The principles of ELISA are addressed to detect the diagnostic traits whereupon the antigens or epitopes of the pathogen are bound with antibodies. The accuracy of ELISA has been greatly improved; use of such commercially available recombinant antibodies are making the diagnosis practically more reliable (López et al., 2001). Some of them are even applicable at the field or at any part of the production and distribution system; for instance, the lateral flow-ELISA is widely utilised for Phytophthora infestans, Ralstonia solanacearum, tomato mosaic virus, the potyvirus group, and many other pathogens (Danks and Baker, 2000). Similarly, tissue print-ELISA and other lateral flow devices are also widely using for site-specific detection.

Other supplementary serological methods have made significant impact on plant disease diagnosis revolution and simultaneously encouraged the identification procedures for many phytopatho systems resulting in precision of quantification for pathogen involvement in a diseased sample. Moreover, the serological methods can also identify the isolates having greater virulence, or having potentiality to identify the isolates resistant to pesticides. In contrast, the quantity or extent of pathogen is not always correlated with disease severity because the pathogen biomass is not (necessarily) directly proportional to the visible expression of disease symptom. Therefore, importance of accurate and quantifiable detection of pathogen in affected plant organ is essentially meaningful in order to diagnose properly and to determine the pesticide load before application.

\section{Flow cytometry (FCM)}

Flow cytometry is an optical technique which uses laser technology. The technique is extensively used for cell counting, cell sorting, biomarker detection and protein engineering. Multiple samples can be simultaneously processed through electronic detection apparatus and the technique measures many parameters simultaneously (Fang and Ramasamy, 2015). Flow cytometry is extensively used for assessment of microorganisms in drinking and marine water, food processing. At present FCM is not extensively utilized in plant pathology as research and detection tool but FCM may have application in plant pathology for multiplexed pathogen detection, assessment of genome size of bacterial, oomycete and fungal pathogens, and for checking viability of the pathogens (D'Hondt et al., 2011).

Serological methods like ELISA are used for the detection of the pathogens like bacteria but these methods cannot assess the viability of the pathogens. Checking viability along with the presence of the pathogen is important criteria for risk assessment of probability of disease development. Therefore, FCM may have potential applications in plant pathology for detection and viability assessment of pathogens in particular bacterial pathogens.

\section{Molecular methods}

Polymerase chain reaction (PCR) is in vitro, primer directed, enzymatic reaction capable of exponential amplification of DNA. The technique has various applications in different branches of biological sciences. Rasmussen and Wulff (1991) were first to apply PCR approach for the detection of a bacterial pathogen in diseased plants. Since then, the approach is widely used as viable alternative for detection and diagnosis of pathogens due to its advantages over conventional methods. PCR based detection assays are specific, sensitive, efficient, rapid, versatile (Henson and French, 1993) and relatively economical. These methods are ideal for detection of pathogen de novo, because they do not require isolation of pathogen in pure culture, thus saving time and resources. Methods involving nucleic acid largely involve DNA as principle nucleic acid, such as fluorescence in-situ hybridization (FISH) and the many PCR variants [PCR, nested PCR (nPCR), cooperative PCR (Co-PCR), multiplex PCR (M-PCR), real-time PCR (RT-PCR), and DNA fingerprinting]. However, a few RNAbased methods like reverse transcriptase PCR, nucleic acid sequence-based amplification (NASBA), and AmpliDet RNA are also useful. All of each mentioned methods are capable for rapid and accurate detection and finally quantification of plant pathogens (López et al., 2009). DNA-based detection methods are reliable and time-saving than the processes of artificial cultivation, and there are higher sensitivity and specificity observed for these methods compared to the traditional and serological assays. The other benefit of the DNAbased methods is the result can be compared with the effect of different treatments. A large quantum of work 
has been conducted with PCR-based methods involving many mould species and plant pathogens. Recently, a PCR-based detection assay revealed confirmation of the pomegranate bacterial blight pathogen, Xanthomonas axonopodis pv. punicae in localised lesions displaying non-translaminar systemic movement (Sharma et al., 2017). The gyrB-based detection further showed the detecting limit of this pathogen; the bacterium could be detected up to $4.0 \mathrm{~mm}$ from the outer margin of the lesion.

Furthermore, parallel to serological methods PCR based assays have both narrow and broad specificities, and are relatively sensitive. In case of PCR test, reliability depends on genetic variability which determines the binding capacity of primers, even in conserved regions of the genome. At the same time mispriming can result from genetic similarity between different pathogens at primer/probe binding sites. Though, PCR has greater sensitivity than other pest detection methods, as more sensitivity is required for important pathogens like Magnaporthe grisea (Balodi and Kumar, 2015) and reliability of the result depends on sampling methods (Martin et al., 2016). The limitations of the hybridisation approach have largely been overcome by the PCR.

Despite potential applications, PCR-based seed assays have not been widely adopted for seed testing. Reasons for this may be presence of secondary compounds and inhibitors in seeds which affect PCR results and errors in quantification of exact amount of pathogen. PCR based assays are unable to estimate the viability of the pathogen, as DNA from non-viable pathogens can be amplified and give an impression of contamination. Since, theoretically, PCR is capable of amplifying a single DNA molecule from reaction mixture, possibility of contamination of commercial reagents with target sequences resulting in false positive is never ruled out. Additionally, formation of non-specific products due to mis-priming and formation of artifacts in form of primer dimers adds more complexities to the probability of correct interpretation. Thus, for wider acceptance of PCRbased assays, it is necessary to address these problems. Solution of these problems and suggested by using Hot Start PCR, using primer with high annealing temperature for increasing specificity, and precautions should be taken to avoid contamination of reagents and working area with target sequences.

\section{Real-time PCR (q PCR)}

Real-time PCR is a variation of conventional PCR, which allows quantification of DNA or RNA in a PCR reaction mixture. With the help of sequence specific primers relative number of copies of a particular DNA or RNA sequence can be estimated by estimating $C_{t}$ value for the sample. If a particular sequence (DNA or RNA) is abundant in the sample, amplification is observed in earlier cycles (low $C_{t}$ value); if the sequence is scarce, amplification is observed in later cycles (high $\mathrm{C}_{t}$ value). Real-time PCR is technically advanced and provides following advantages over conventional PCR. (1) it allows real-time monitoring of $\mathrm{PCR}$ reaction, (2) it enables measurement of amplicon after each cycle, (3) it increases range of detection of target sequence hence increases sensitivity of the assay, and (4) since estimates are done in real time it does not require post-amplification steps of gel electrophoresis thus saving time and resources (Invitrogen).

With real-time PCR, DNA amplification is coupled with the production of a fluorescent signal that increases proportionally with the numbers of amplicons produced (Cockerill and Smith, 2002). The fluorescent signal is monitored on a computer in real-time and provides an indirect visual representation of DNA amplification. Detection of amplified DNA can be accomplished by staining with SYBR Green I (Molecular Probes Inc., Eugene Ore.) that binds double-stranded DNA indiscriminately or with the use of specific reporter probes like TaqMan (Applied Biosystems, Foster City, Calif.) (Taylor et al., 2002). TaqMan probes are synthesized with reporter and quencher molecules at the $5^{\prime}$ and $3^{\prime}$ ends respectively. These probes work on the principle of fluorescent resonance energy transfer (FRET). When reporter and quencher dye are proximal to each other there is no fluorescence, and when they separate reporter dye fluoresces. The change in fluorescence is detected by photosensors and change in intensity is directly proportional to DNA amplification. Other detection systems including and molecular beacon probes are also employed for real-time PCR, these also work on the same principles as TaqMan probe (Cockerill and Smith, 2002).

Real-time PCR offers key advantages that make it more acceptable than conventional PCR for routine seed testing viz., rapid cycling and real time analysis of PCR products makes it user friendly and well suited for swift analysis, reduction in cross contamination due to closed system, reaction can be multiplexed with multiple probes and primers (Wittwer et al., 2001). Real-time PCR can allow quantification of template DNA which may be of use in determining levels of seed infection. Though cost involved in real-time PCR-based detection is key constraint in its adoption as a routine technique in seed testing laboratories, but advantages are more than economics involved.

To date, real-time PCR seed detection assays have been reported for Acidovorax avenae subsp. citrulli in watermelon seeds, Microdochium nivale in wheat seeds (Taylor et al., 2002), Ralstonia solanacearum race 3, biovar 2, in asymptomatic potato tubers (Ozakman and Schaad, 2003), fungal and oomycete tomato pathogens in plant and soil samples (Lievens et al., 2006), Rhizoctonia solani AG-1 IA in rice (Sayler and Yang, 2007), Fusarium circinatum in pine seed (loos et al., 2009), Xanthomonas arboricola pv. pruni in Prunus species (Palacio-Bielsa et al., 2011), Xanthomonas oryzae pv oryzae in rice by Real time Bio-PCR (Cho et al., 2011).

\section{Role of bioinformatics in plant disease diagnosis}

Bioinformatics employs application of information communication technology in biological research. It is 
an emerging area of biological sciences having applications in biotechnology and molecular biology. It is an interdisciplinary branch of biology using concepts of informatics, statistics, mathematics, chemistry, biochemistry, physics and linguistics, having applications in biology and medicine. Bioinformatics has applications in mapping, analysing and aligning different DNA and protein sequences, formation of 3-D structures of molecules. Further, bioinformatics tools can be used for data management, analysis for making scientific discovery primarily in agriculture and healthcare sectors (Jayaram and Dhingra, 2010). For development of plant diagnostic tools trait of interest are biotic and abiotic stress resistance, quality traits of interest (Koltai and Volpin, 2003), traits related to specific symptom development in a disease and specific traits of pathogens.

\section{CONCLUSION}

The science of plant disease diagnostics has progressed in technological advancements from the visual inspection of signs and symptoms of disease to molecular level detection of the pathogens. Sensitive and accurate detection of plant pathogens is important for management of the plant diseases and checking spread of pathogens to previously uninvaded areas. The advancements in the field of plant pathology, coupled with biotechnology, bioinformatics and molecular biology have opened new avenues for development of specific and sensitive procedures of diagnosis. Plating assays like blotter method, towel paper test provide information about presence and viability of the pathogens but these methods are time-consuming, labour intensive and at the same time have low specificity and sensitivity.

Molecular methods like PCR, quantitative PCR along with serological methods and flow cytometry may be alternative to conventional methods. These methods have high sensitivity and specificity and are less timeconsuming. But at the same time, it is required that these methods should be standardized to meet the requirements of specificity and sensitivity. Further, standardized protocols are needed for global acceptance of the method as standard protocol for quarantine purposes.

\section{REFERENCES}

Ansar M and Singh RP (2016). Field diagnosis and temporal progress of Potato Virus $X$ and $A$ in tarai region of Uttarakhand. J. Mycol. PI. Pathol. 46: 368-373.

Balodi R and Kumar J (2015). PCR Assay for rapid and accurate detection of Magnaporthe oryzae in rice (Oryza sativa) using primers specific to PWL gene family. J. Mycol. PI. Pathol. 45: 144-1455.

Brownlie J, Peckham C, Waage J, Woolhouse M and Lyall C (2006). Foresight. Infectious Diseases: Preparing for the Future-Future Threats. London: Office of Science and Innovation.

Cho MS, Kang MJ, Kim CK, Seol YJ, Hahn JH, Park SC, Hwang DJ, Ahn TY, Park DH, Lim CK and Park DS (2011). Sensitive and specific detection of Xanthomonas oryzae pv. oryzae by real-time bio-PCR using pathovar-specific primers based on an rhs family gene. Pl. Dis. 95: 589-594.
Chou Q, Russell M, Birch DE, Raymond J and Bloch W (1992). Prevention of pre-PCR mis-priming and primer dimerization improves low copy-number amplifications. Nucleic Acids Res. 20: 17-23.

Candresse T, Filloux D, Muhire B, Julian C and Galzi S (2014). Appearances can be deceptive: revealing a hidden viral infection with deep sequencing in a plant quarantine context. PLOS ONE 9: e102945.

Caruso P, Gorris MT, Cambra M, Palomo JL, Collar J and López MM (2002) Enrichment double-antibody sandwich indirect enzyme-linked immunosorbent assay that uses a specific monoclonal antibody for sensitive detection of Ralstonia solanacearum in asymptomatic potato tubers. Appl. Environ. Microbiol. 68: 3634-3638.

Clark MF (1981). Immunosorbent assays in plant pathology. Annu. Rev. Phytopathol. 19: 83-106.

Cockerill FR and Smith TF (2002). Rapid-cycle real-time PCR: A revolution for clinical microbiology. American Society of Microbiological News 88: 77-83.

Danks C and Baker I (2000). On-site detection of plant pathogens using lateral-flow devices. EPPO Bull. 30: 421426.

D'hondt L, Hofte M, Van Bockstaele E and Leus L (2011). Applications of flow cytometry in plant pathology for genome size determination, detection and physiological status. Mol. Plant Pathol. 12: 815-828.

Fang $Y$ and Ramasamy RP (2015). Current and prospective methods for plant disease detection. Biosensors 4: 537561.

FAO (2004). Pest risk analysis for quarantine pests, including analysis or environmental risks and living modified organisms. Int. Stand. Phytosanit. Meas. Number 11, Food Agric. Organ., Rome.

FAO (2007). Framework for pest risk analysis. Int. Stand. Phytosanit. Meas. Number 2, Food Agric. Organ., Rome.

FAO (2009). Global agriculture towards 2050-High level expert forum. Rome, Itlay: FAO, UN.http://www.fao.org/fileadmin/ templates/wsfs/docs/ls sues_papers/ HLEF2050_Global_Agriculture.pdf

Godfray HCJ, Beddington JR, Crute IR, Haddad L, Lawrence D, Muir JF, Pretty J, Robinson S, Thomas SM and Toulmin C (2010). Food security: The challenge of feeding 9 billion people. Science 327: 812-818.

Guo M, Lan J, Shi J, Guan M and Wei J (2015). Western blot detection of Xanthomonas Oryzae pv. oryzae in rice. J. Plant Pathol. Microbiol. S4: 005.

loos R, Fourrier C, lancu G and Gordon TR (2009). Sensitive detection of Fusarium circinatum in pine seed by combining an enrichment procedure with a real-time polymerase chain reaction using dual-labeled probe chemistry. Phytopathology 99: 582-590.

Jayaram B and Dhingra $P$ (2010).Bioinformatics for a better tomorrow. Indian Institute of Technology, Hauz Khas, New Delhi - 110016, India.

Lievens B, Brouwer M, Vanachter ACRC, Cammue BPA and Thomma BPHJ (2006). Real-time PCR for detection and quantification of fungal and oomycete tomato pathogens in plant and soil samples. Plant Sci. 171: 155-165.

López MM, Llop P, Cubero J, Penyalver R, Caruso P, Bertolini E, Penalver J, Gorris MT and Cambra M (2001). Strategies for improving serological and molecular detection of plant pathogenic bacteria. Plant Pathogenic Bacteria; Springer: Berlin, Germany, pp. 83-86. 
López MM, Llop P, Olmos A, Marco-Noales E, Cambra M and Bertolini E (2009). Are molecular tools solving the challenges posed by detection of plant pathogenic bacteria and viruses? Mol. Biol. 11: 13-14.

Mahlein AK (2016). Plant disease detection by imaging sensorsparallels and specific demands for precision agriculture and plant phenotyping. Pl. Dis. 100: 241-251.

Martin RR, Constable F and Tzanetakis IE (2016). Quarantine regulations and the impact of modern detection methods. Annu. Rev. Phytopathol. 54: 189-205.

Mesterházy Á, Lemmens M and Reid LM (2012). Breeding for resistance to ear rots caused by Fusarium spp. in maize a review. Plant Breed. 131: 1-19.

Miller SA, Beed FD and Harmon CL (2009). Plant disease diagnostic capabilities and networks. Annu. Rev. Phytopathol. 47: 15-38.

Musetti R, Loi N, Carraro L and Ermacora P (2002). Application of immunoelectron microscopy techniques in the diagnosis of phytoplasma diseases. Microsc. Res. Tech. 56: 462-464.

Murillo-Williams A and Munkvold GP (2008). Systemic infection by Fusarium verticillioides in maize plants grown under three temperature regimes. Pl. Dis. 92: 1695-1700.

Mutka AM and Bart RS (2015). Image-based phenotyping of plant disease symptoms. Front. Plant Sci. 5: 734.

Narayanasamy P (2011). Detection of fungal pathogens in plants. Microbial plant pathogens-detection and disease diagnosis: Fungal Pathogens 1: 5.

Ozakman M and Schaad NW (2003). A real-time Bio-PCR assay for detection of Ralstonia solanacearum race 3, biovar 2, in asymptomatic potato tubers. Can. J. PI. Pathol. 25: 232239.

Paul Khurana SM (2006). Detection of plant pathogens: development and applications. Indian Phytopath. 59:1-15.

Palacio-Bielsa A, Cubero J, Cambra MA, Collados R, Berruete IM and Lo'pez MM (2011). Development of an efficient Real-Time Quantitative PCR Protocol for detection of Xanthomonas arboricola pv. pruni in Prunus Species. Appl. Environ. Microbiol. 77: 89-97.
Rasmussen OF and Wulff BS (1991). Detection of Pseudomonas syringae pv. pisi using PCR. In: Proceedings of 4th International Working Group, Kluwer Academic Publishers, Dordrecht, and Nederland. pp: 367-376.

Riley MB, Williamson MR and Maloy O (2002). Plant disease diagnosis. Plant Health Instr. doi: 10.1094/PHII-2002-102101.

Rochelle PA, Weightman AJ and Fry JC (1992). DNasel treatment of Taq DNA polymerase for complete PCR decontamination. Biotechniques 13: 520.

Saksena NK, Dwyer D and Barre-Sinoussi F (1991). A "sentinel" technique for monitoring viral aerosol contamination. J. Infect Dis. 164: 1021-22.

Sayler RJ and Yang Y (2007). Detection and quantification of Rhizoctonia solani AG-1 IA, the rice sheath blight pathogen, in rice using real-time PCR. PI. Dis. 91: 16631668.

Sharma J, Sharma KK, Kumar A, Mondal KK, Thalor S, Maity A, Gharate R, Chinchure S and Jadhav VT (2017). Pomegranate bacterial blight: symptomatology and rapid inoculation technique for Xanthomonas axonopodis pv. punicae. J. Plant Pathol. 99: 109-119.

Strange RN and Scott PR (2005). Plant disease: a threat to global food security. Annu. Rev. Phytopathol. 43: 83-116.

Taylor E, Bates J, Kenyon D, Maccaferri M and Thomas J (2002). Modern molecular methods for characterisation and diagnosis of seed-borne fungal pathogens. J. Pl. Pathol. 83: $75-81$.

Wang Z, Yu D, Li X, Zeng M, Chen Z, Bi L, Liu J, Jin L, Hu D Yang S and Song B (2012). The development and application of a Dot-ELISA assay for diagnosis of southern rice black-streaked dwarf disease in the field. Viruses 4: 167-183.

Wittwer CT, Herrmann MG, Gundry CN and Elenitoba-Johnson KS (2001). Real-time multiplex PCR assays. Methods. 25: 430-442. 